
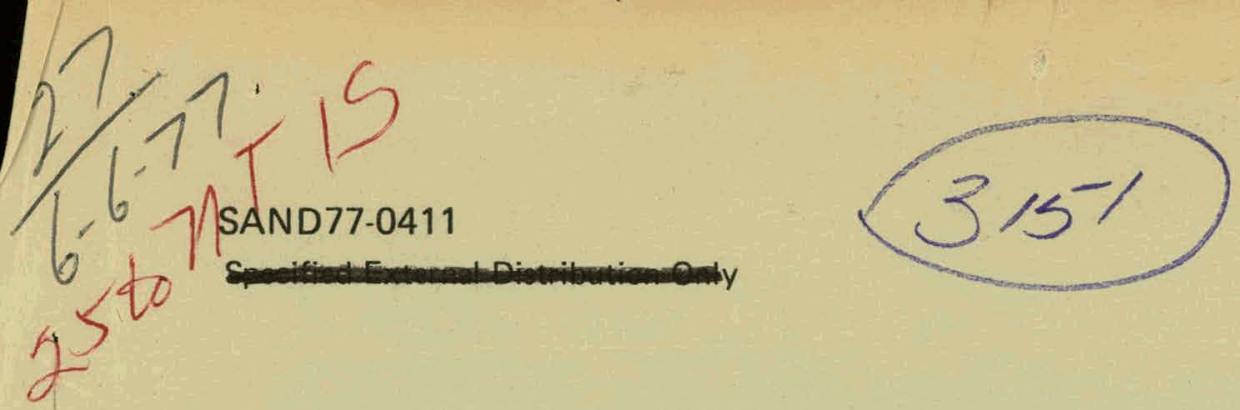

\title{
The Use of Hysol USO009 Polyurethane Encapsulant in Battery Cables
}

George Voida

Prepared by Sandia Laboratories, A lbuquerque, New Mexico 87115

and Livermore, California 94550 for the United States Energy Research

and Development Administration under Contract AT (29-1)-789

Printed April 1977 


\section{DISCLAIMER}

This report was prepared as an account of work sponsored by an agency of the United States Government. Neither the United States Government nor any agency Thereof, nor any of their employees, makes any warranty, express or implied, or assumes any legal liability or responsibility for the accuracy, completeness, or usefulness of any information, apparatus, product, or process disclosed, or represents that its use would not infringe privately owned rights. Reference herein to any specific commercial product, process, or service by trade name, trademark, manufacturer, or otherwise does not necessarily constitute or imply its endorsement, recommendation, or favoring by the United States Government or any agency thereof. The views and opinions of authors expressed herein do not necessarily state or reflect those of the United States Government or any agency thereof. 


\section{DISCLAIMER}

Portions of this document may be illegible in electronic image products. Images are produced from the best available original document. 
Issued by Sandia Laboratories, operated for the United States Energy Research \& Development Administration by Sandia Corporation.

\section{NOTICE}

This report was prepared as an account of work sponsored by the United States Government. Neither the United States nor the United States Energy Research \& Development Adminis. tration, nor any of their employees, nor any of their contractors, subcontractors, or their employees, makes any warranty, express or implied, or assumes any legal liability or responsibility for the accuracy, completeness or ussfulness of any information, apparatus, product or process disclosed, or represents that its use would nut infringe privately owned rights. 
The Use of Hysol US0009 Polyurethane Encapsulant in Battery Cables

\author{
George Voida \\ Interconnections Division 2154 \\ Sandia Laboratories \\ Albuquerque, New Mexico 87115
}

Abstract

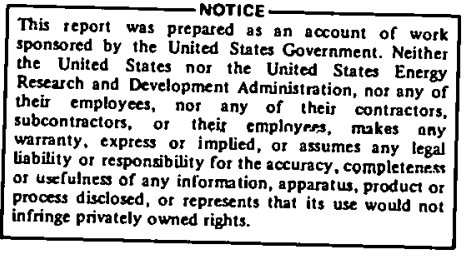

This report describes the evaluation of Hysol USO009 polyurethane as an encapsulant for the battery cable used on the MC1605B. The Hysol resin was selected for the application because it was reacted with a non-carcinogenic curing agent and because it exhibited superior mechanical, electrical, and hydrolytic properties over a wide temperature range.

The Hysol encapsulant was evaluated to determine if it was superior to the EN-7 elastomer as a sealant against electrolyte migration to the interior of the cable. Environmental tests reported here showed the Hysol was marginal when no preseal was employed but was $100 \%$ effective when a bird-cage seal was used inside the EMR hardware. The EN-7 encapsulant, on the other hand, was effective only when seals were employed both inside the EMR hardware as well as at the lug terminations. Without the two preseals, the EN-7 compound was always unsatisfactory.

Twenty development battery cables fabricated with Hysol under production operations were tested after alternate immersion in battery electrolyte and after exposures to temperature shock and the MIL-STD 202 environment. Presealed cables successfully survived these exposures and retained their initial DC resistance, insulation resistance, and high potential properties with only minor changes.

The environmental tests conducted with these assemblies probably represented five or more years of in-field service.

Comparative peel tests demonstrated that the Hysol/neoprene insert bond was twice $(5.2$ versus $2.8 \mathrm{~kg} / \mathrm{cm}$ ) that of the EN-7 polyurethane.

Hysol USOOO9 has a potential for encapsulation of other WR components and assemblies in which the EN- 7 resin has exhibited thermal short comings. 
Acknowledgement

The author wishes to express his appreciation to B. P. Neumon, Interconnections Division 2154, for his assistance with the electrical and electrolyte immersion testing of the cables evaluated for this report. 
Introduction

Development Cables (P.0. 04-7032) 9

Materials of Construction 9

Encapsulation with Hysol USO009 Elastomer 9

Test Results on Hysol US0009 Elastomer 11

Comparative Properties of Polyurethane Elastomers 15.

Peel Strength of Hysol US0009 Casting to Neoprene Rubber 15

Tests of Development Cables 17

$\begin{array}{ll}\text { Electrical Tests } & 17\end{array}$

Electrolyte Immersion Tests 20

Effects of Temperature Shock 23

Effects of MIL-STD 202 Exposure . . . . . 23

Future Work $\quad 24$

Conclusions 24

References $\quad-\quad \ldots \quad \cdot \quad 28$ 


\section{List of Tables}

$\underline{\text { Table }}$

Page

1 Materials of Construction 10

2 Process and Acceptance Specifications for Battery Cable 12

3 Test Results - Hysol US0009 14

4 Comparative Properties of Polyurethane Elastomers . 16

$5180^{\circ}$. Peel Test Results (Hysol Us0009 Cast to Neoprene Rubber) 18

6 Identity of Development Battery Cables $\quad 19$

7 Electrical Testing of Bird-Caged Cables Units 1-10 21

8 Electrical Testing of Units 11-20 Not Bird-Caged 22

9 Initial and Final DC Resistance Tests of Battery Cables 25

10 Initial and Final Insulation Resistance Tests of Battery Cables 26

List of Illustrations

Figure

Page

1. Unravelled and "Bird-Caged" Wire Strands $7 \mathrm{X} \quad 6$

2 Resin Coated "Bird-Cage" 2.5X 6

3 Resin Coated "Bird-Cage" and H-S Sleeving in Place 7X $\quad \cdots \quad 7$

4 Completed "Bird-Cage" Seal $7 \mathrm{X} \quad 7$

5 "Bird-Cage" Of Wire Strands Adjacent To Lug 8

6 Heat Shrinkable Sleeving Over "Bird-Cage" At Lug 8

7 TheP/N 197541 Cable Assembly 13 
The Use of Hysol US0009 Polyurethane

Encapsulant in Battery Cables

\section{Introduction}

This report describes the evaluation of Hysol US0009* polyurethane as an encapsulant for the battery cable on the MC1605B. The Hysol compound was used as a potential sealant to prevent the migration of battery electrolyte to the interior of the cable.

The Hysol resin was selected for evaluation because it is a non-MOCA** and non-TDI** polyurethane elastomer and it possesses superior mechanical, electrical, and hydrolytic properties over a wide temperature range. ${ }^{1}$ The EN-7 polyurethane compound which is currently used provides only marginal bonding to the connector inserts. In order to enhance sealing in the present study the wire strands of the conductors (inside the EMR hardware) were flaired or "bird-caged" so as to achieve an impenetrable seal.

The "bird-cage" procedure consists of separating the strands (Figure 1), coating them with thickened Hysol resin (Figure 2), and then enveloping the junction with heat-shrinkable sleeving (Figure 3). The completed seal at the cable connector is shown in Figure 4. Since each wire strand is surrounded with sealant, the electrolyte is constrained from creeping beyond this barrier. The same procedure was followed in providing the "bird-cage" seal at the lug terminations with the EN-7 elastomer (Figures 5 and 6 ).

The development cables used in these evaluations were assembled in a production facility at Bendix Electronics Components Division (BECD). The cables were alternately immersed in electrolyte and then subjected first to temperature shock and

\footnotetext{
*Hysol Division, The Dexter Corp., Olean, N. Y. **MOCA-Methylene-bis-ortho-chloroaniline. TDI-toluene diisocyanate
} 


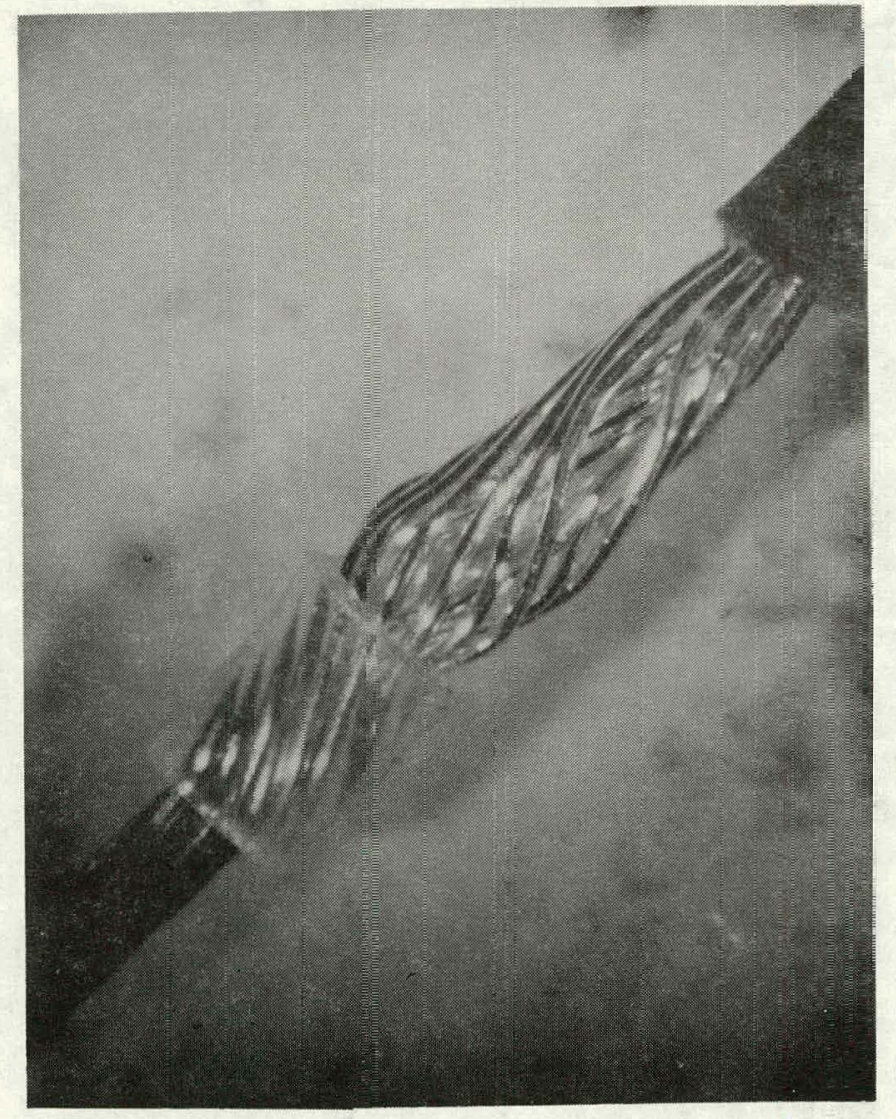

Fig. 1 Unravelled And "Bird-Caged" Wire Strands $7 X$

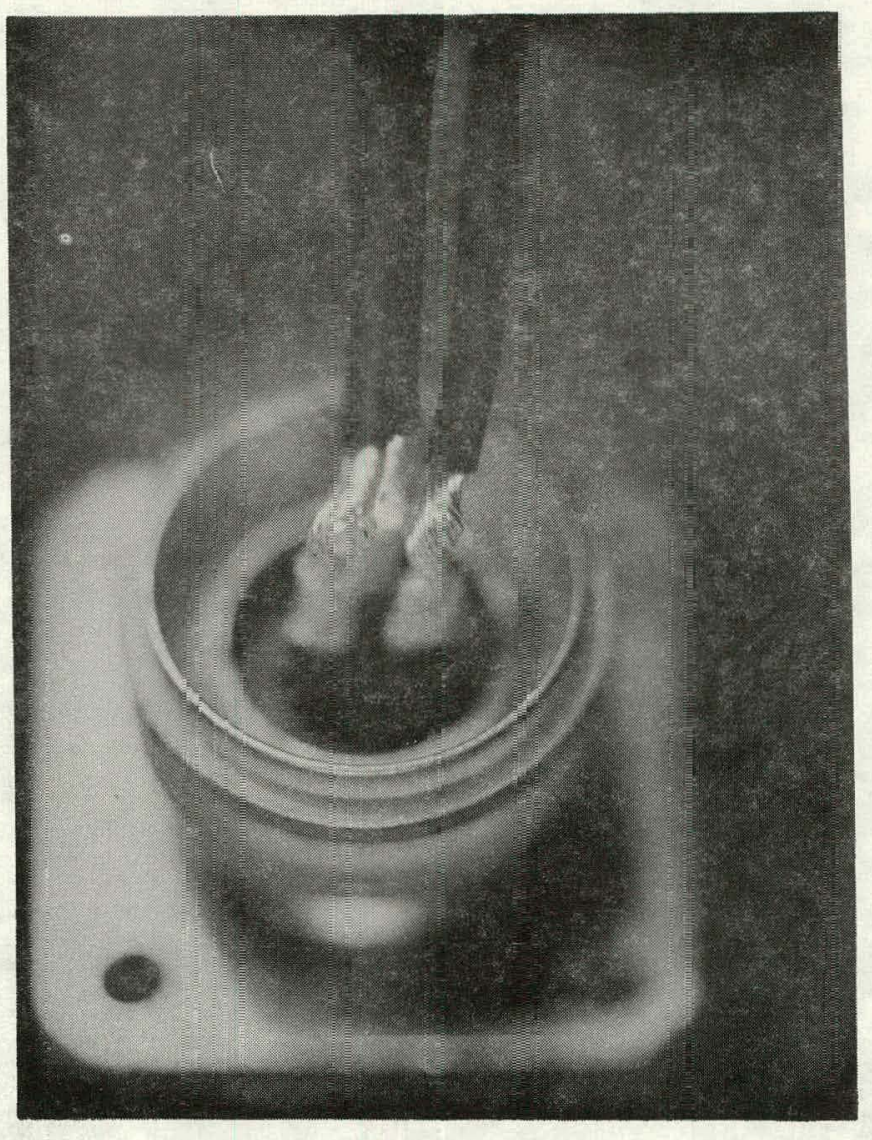

Fig. 2 Resin Coated "Bird-Cage" 2.5X 


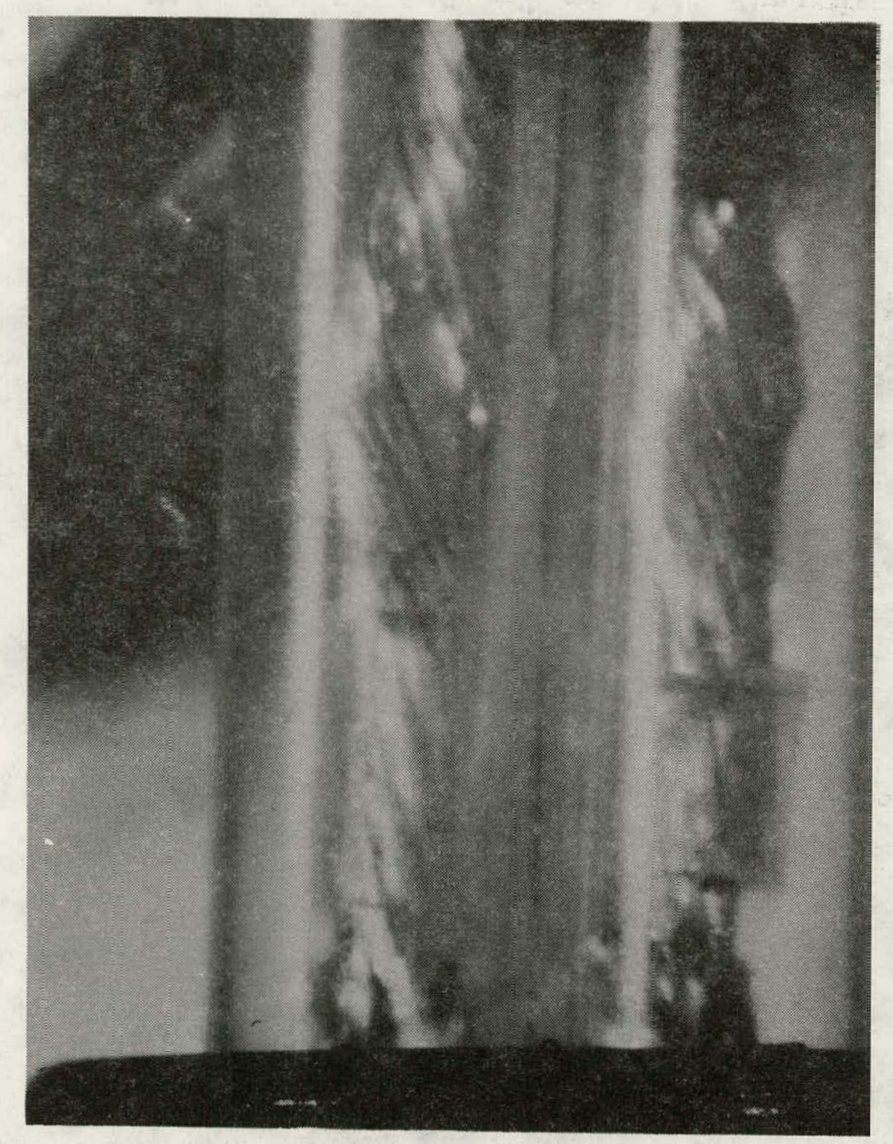

Fig. 3 Resin Coated "Bird-Cage" and $\mathrm{H}-\mathrm{S}$ Sleeving in Place $7 \mathrm{X}$

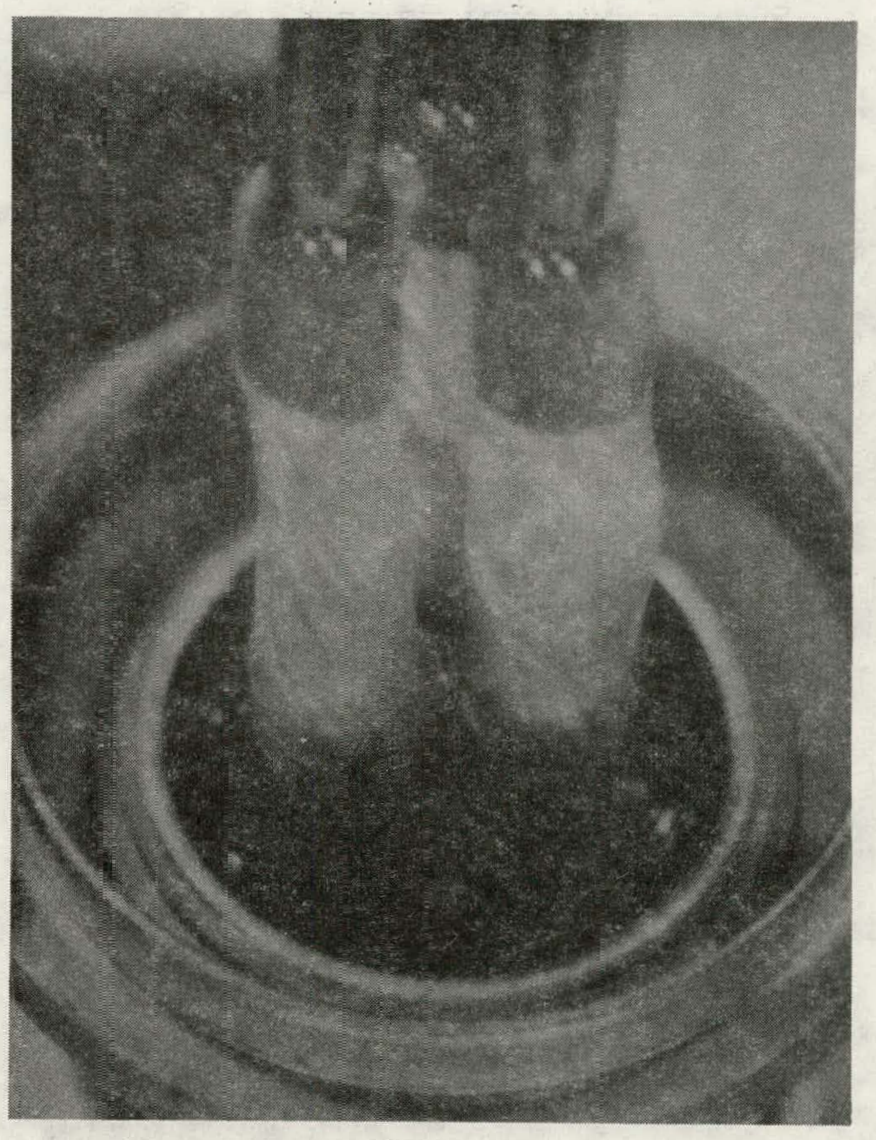

Fig. 4 Completed "Bird-Cage" Seal 7X 


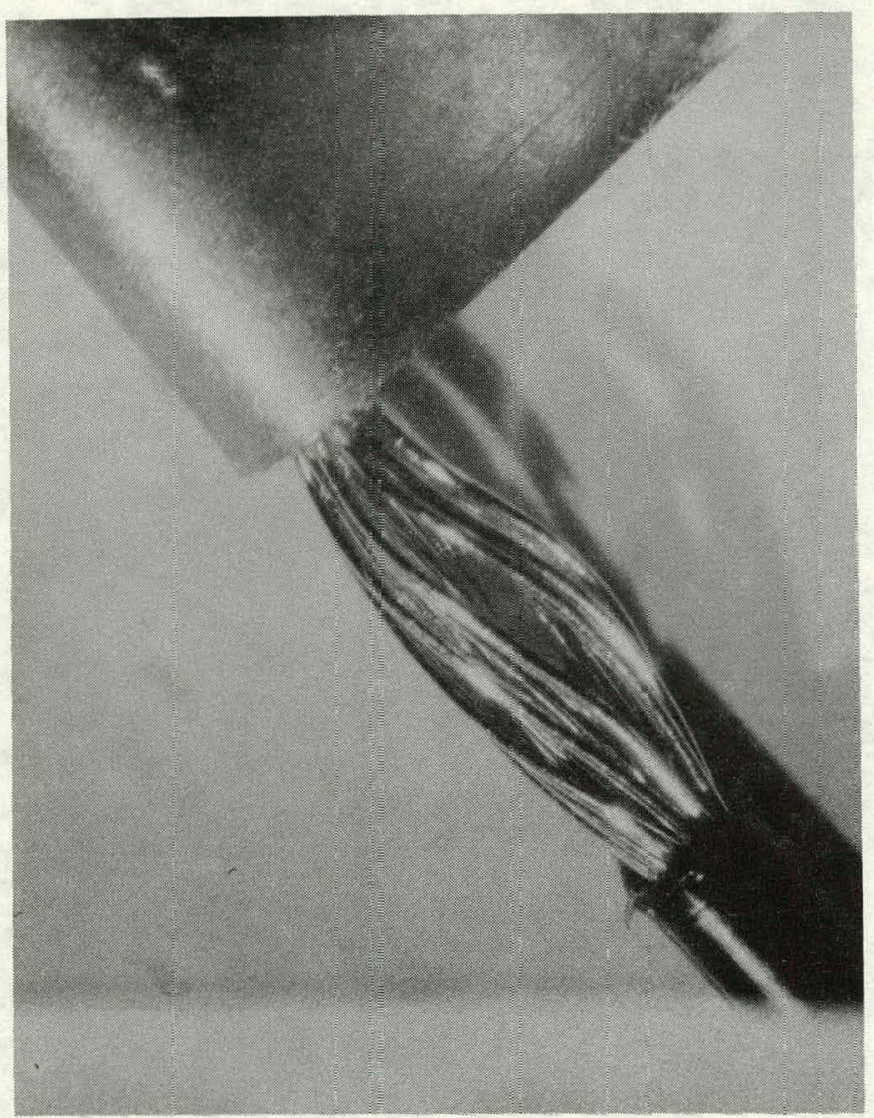

Fig. 5 "Bird-Cage" of Wire Strands Adjacent to Lug

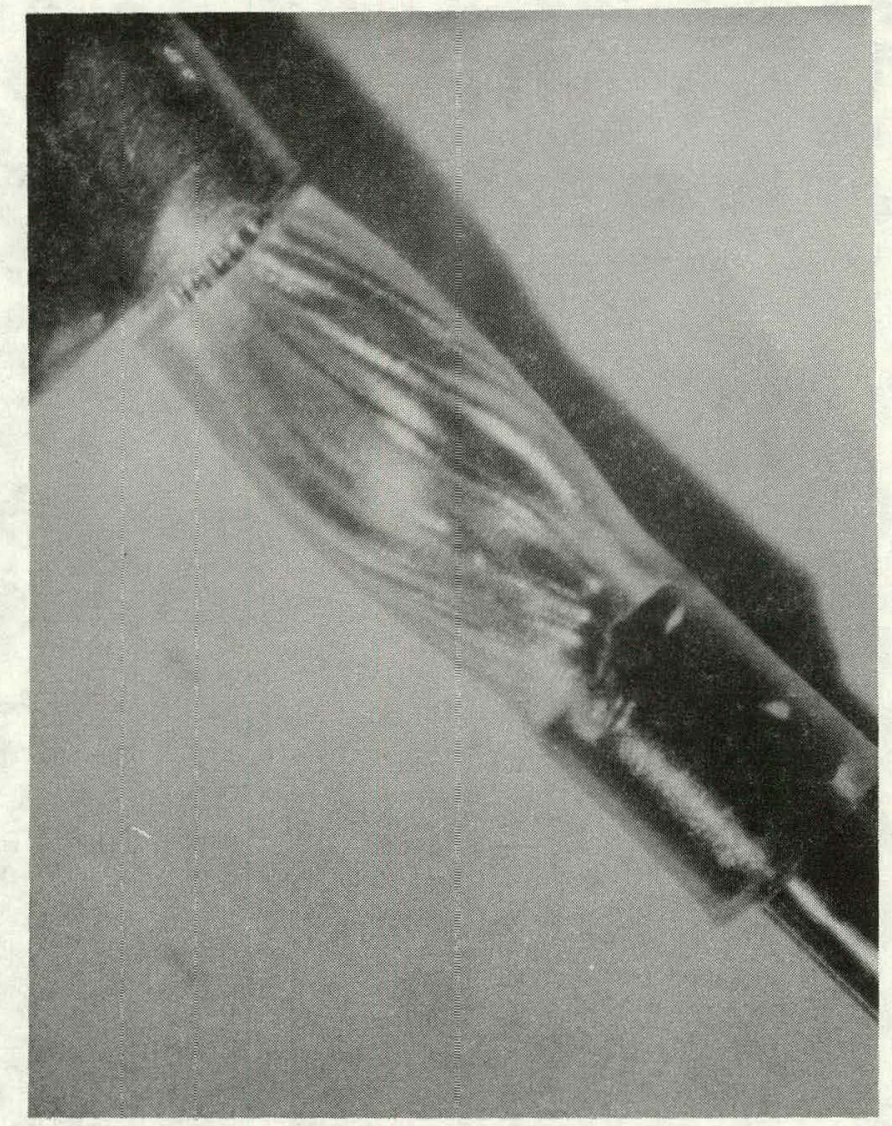

Fig. 6 Heat Shrinkable Sleeving Over "Bird-Cage" 
next to the MIL-STD 202 environment. The "bird-caged" units successfully passed all of the tests. Three of ten units not "bird-caged" failed the high potential test after the final exposure to the MIL-STD 202 environment.

In cables not sealed with a "bird-cage", the potassium hydroxide electrolyte will seep to the neoprene/Hysol interface and will disrupt the bond between the two materials. This results in a short circuit between the connector pins.

\section{Development Cables (P.0. 04-7032)}

Bendix Electronic Component Division (BECD) was contracted to fabricate the development units used in this evaluation since this facility had successfully produced these assemblies with the Adiprene/MOCA elastomer over a period of eight years. 2,3 Recently BECD had evaluated the Hysol US0009 polyurethane compound as an encapsulant for other of its product lines and was therefore familiar with the processing characteristics of the resin.

\section{Materials of Construction}

Except for the use of the Hysol encapsulant and the use of unprimed surface of the neoprene connector insert, the battery cable was built with the materials listed in Table 1.

\section{Encapsulation with Hysol US0009 Elastomer}

The cable assembly was encapsulated with Hysol US0009* polyurethane by the two step process described in paragraph 3.2 of S\$282906. The properties and the processing of the Hysol compound are described in BECD Specification 9-7300. The elastomer was prepared by mixing 100 parts by weight of Part A resin, 35 parts of Part B curing agent, and two parts of black BECD \#643 dispersion pigment per BECD Specification $9-5322$.

* Presumably equivalent to Hysol US4001 
TABLE 1

\section{MATERIALS OF CONSTRUCTION}

Part Number

354949

298463

877023

877024

281189

179983

877136

8220709-02-821

MIL-W-22759/6

MIL-W-22759/6

7900303

7900313

9-7300 (BECD)

9927087
Description

Connector SA-1077-3

Adapter Ring (Brass Per MIL-B-13492, Sn/Pb Plated)

Shel1 (Brass Per QQ $-B-813$ )

Ferrule (Brass Per QQ-B-813)

Terminal Lug (Nickel)

Terminal Lug (Nickel)

Grommet Rubber (Neoprene)

Conductor, $20 \mathrm{AWG}$, White, TFE Insulated

Conductor, 20 AWG, Black (Nickel Clad Copper 19/32)

(ASTM 355, Class 27. Outer Insulation Must Be

Bondahle). วN\% minimum nickel by wөight.

Conductor, 20 AWG, White (Nickel Clad Copper 19/32) (AsTM 355, Class 27. Outer Insulation Must Be Bondable). 20\% minimum nickel by weight.

Braid, Nickel Wire, $0.13 \mathrm{~mm}$ Dia. Annealed/MIL-N-46026

$$
\begin{aligned}
& \text { Number ends/carrier }-1 \\
& \text { Number of carriers }-24 \\
& \text { Minimum coverage }-80 \% \\
& \text { Q.D. of shield }-3.8 \mathrm{~mm}
\end{aligned}
$$

Braid, Nickel Wire, $0.13 \mathrm{~mm}$ Dia. (Optional)

Polyurethane compound, Hysol USUOUY, Parts A and B Encapsulation Process 
The $A$ and $B$ ingredients were pre-warmed and re-blended prior to mixing in order to ensure a uniform mixture of the final encapsulant. The compound throughout the processing was purposely handled only in special types of vessels so as to prevent its contamination. The mixed compound was degassed and then introduced into a warm mold so as to avoid the inclusion of air bubbles or voids into the casting.

The encapsulant was then cured for 1 to 1.5 hours at $100 \pm 5^{\circ} \mathrm{C}$. This cure schedule was at variance ${ }^{4}$ with the one proposed by the resin manufacturer who recommended $2-3$ days at room temperature or 4 hours at $60^{\circ} \mathrm{C}$. BECD could not explain the discrepancy of its cure schedule. The schedule was probably selected because it allowed a rapid turn around of the casting molds. In future investigations it will be necessary to evaluate castings produced with both cure cycles in order to determine the equivalency in properties of each product.

The Sandia Specifications which control the processing and the acceptance of the battery cable are listed in Table 2. The completed cable assembly P/N 197541 is shown in Figure 7.

Test Results on Hysol USO009 Elastomer

Bendix ECD conducted a series of tests on the Hysol encapsulant to determine effects of elevated temperatures and high humidity exposures. The data are presented in Table 3. During comparative studies at room temperature and $150^{\circ} \mathrm{C}$, the dissipation factor increased from 0.016 to 0.0345 ; the volume resistivity dropped from $3.6 \times 10^{13}$ to $6.7 \times 10^{11} \Omega \cdot \mathrm{cm}$; and the dielectric constant rose from 4.67 to 5.27 .

The Shore A hardness dropped 10 points from 92 to 82 over the same temperature excursion. For a polyurethane elastomer to retain this property under such 
TABLE 2

PROCESS AND ACCEPTANCE SPECIFICATIONS FOR BATTERY CABLE

Sper. Nimber AY197541, Issue L

197541, Issue T

PS197541, Is sue $\mathrm{H}$

SS282906, Is sue $\mathrm{K}$

9-7300 (BECD)

AF360700-002

9926018

\section{Description}

Graphic, Cable Assembly, Special Purpose, Electrical

Cablc Asscmbly, Epccial Furposc, Elcctrical

Battery Cable Pigtail

Fabrication, Battery Cable, Pigtail for MC1605B

Encapsulating Compound, Polyurethane, High Strength

Battery Cable Test with 65802 Adapter

Protection and Repair, Multi-Contact

Electrical Connectur 


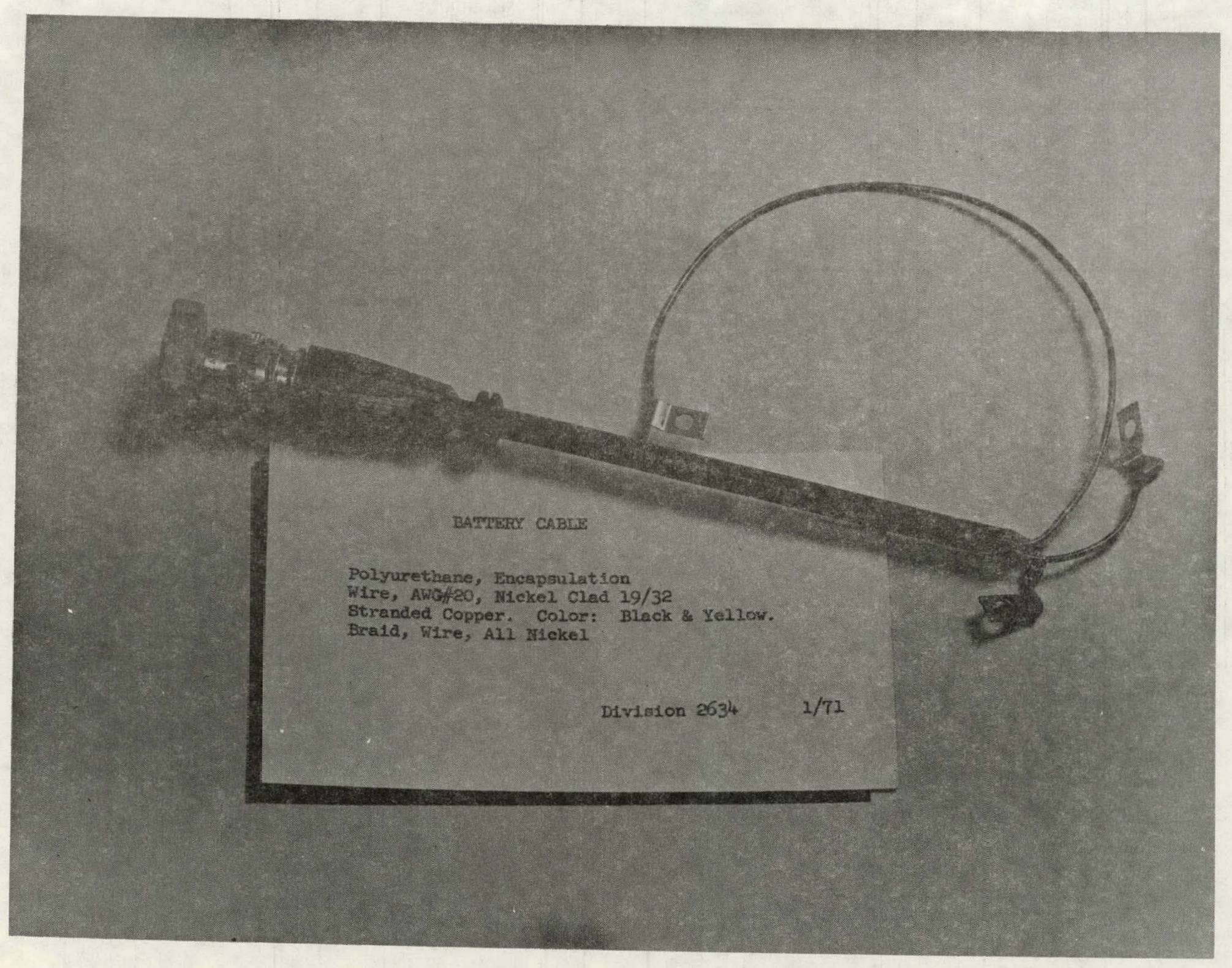


TABLE 3

TEST RESULTS - HYSOL-USOOO9

\begin{tabular}{|c|c|c|c|c|}
\hline Electrical Data & $23^{\circ} \mathrm{C}$ & $100^{\circ} \mathrm{C}$ & $125^{\circ} \mathrm{C}$ & $150^{\circ} \mathrm{C}$ \\
\hline $\begin{array}{l}\text { Dissipation Factor, } 1000 \mathrm{~Hz} \\
\text { Volume Resistivity, } \Omega \cdot \mathrm{cm} \\
\text { Dielectric Constant } \\
\text { Dielectric Strength } \mathrm{MV} / \mathrm{m}\end{array}$ & $\begin{array}{l}.016 \\
3.61 \times 10^{13} \\
4.67 \\
17.2\end{array}$ & $\begin{array}{l}.016 \\
1.69 \times 10^{12} \\
4.27\end{array}$ & $\begin{array}{l}.016 \\
4.81 \times 10^{11} \\
4.18\end{array}$ & $\begin{array}{l}.0345 \\
6.72 \times 10^{11} \\
5.27\end{array}$ \\
\hline
\end{tabular}

\begin{tabular}{|c|l|l|l|l|}
\hline Physical Properties - Cured & & & \\
\hline \hline Hardness, Shore A & $92 @ ? 3^{\circ} \mathrm{C}$ & & \\
& $90 @ 100^{\circ} \mathrm{C}$ & & & \\
(Room temperature properties) & $86 @ 125^{\circ} \mathrm{C}$ & & & \\
Specific Gravity & $820150^{\circ} \mathrm{C}$ & & \\
Tensile Strength, MPa & 1.072 & & \\
Elongation, \% & 35.5 & & \\
Tear Strength, N/m & 325 & & \\
\hline
\end{tabular}

\begin{tabular}{|l|l|c|c|c|}
\hline Humidity Data $-80^{\circ} \mathrm{C} / 95 \% \mathrm{R} . \mathrm{H}$. & & & & \\
\hline \hline Exposure Time & original & $264 \mathrm{hr}$ & $1200 \mathrm{hr}$ & $2832 \mathrm{hr}$ \\
Dissipation Factor & .016 & .030 & .031 & .033 \\
Volume Resistivity, $\Omega \cdot \mathrm{cm}$ & $1.9 \times 10^{13}$ & $1.27 \times 10^{12}$ & $1.28 \times 10^{12}$ & $1.32 \times 10^{14}$ \\
Dielectric Constant & 4.98 & 5.73 & 5.70 & 5.66 \\
Hardness, Shore A & 91 & 91 & 93 & 93 \\
\hline
\end{tabular}

Humidity Date $33^{\circ} \mathrm{C} / 3.0 \% \% \mathrm{R} . \mathrm{IT}$.

Exposure Time

Dissipation Factor

Volume Resistivity, $\Omega \cdot \mathrm{cm}$

Dielectric Constant

Hardness, Shore A original

.0145

$1.2 \times 10^{14}$

5.52

94
$1152 \mathrm{hr}$.

\begin{tabular}{ll}
\hline 15 min. after & Dry $4 \mathrm{hr} . @ 65^{\circ} \mathrm{C}$ \\
removal & .021 \\
.040 & $8 \times 10^{13}$ \\
$4.8 \times 10^{11}$ & 5.34 \\
6.25 & 93 \\
93 & 9
\end{tabular}


conditions is unusual. The EN-7 encapsulant under such exposure would soften beyond the point of supporting its own weight.

The data in Table 3 also illustrate how constant the dissipation factor, the volume resistivity, the dielectric constant, and the hardness remained upon exposure of the Hysol compound to $80^{\circ} \mathrm{C}$ and $95 \% \mathrm{RH}$ for a total of 2832 hours. The same type of test was also conducted at $93^{\circ} \mathrm{C}$ and $95 \% \mathrm{RH}$ for 1152 hours. The absorbed moisture had a temporary effect on the properties mentioned above. After the compound was dried for 4 hours at $65^{\circ} \mathrm{C}$, the original properties were almost completely restored.

Comparative Properties of Polyurethane Elastomers

The corresponding properties of Adiprene, EN-7, and the equivalent Hysol polyurethane elastomers are presented in Table 4. There is a general agreement in properties except for the tensile strength and elongation of the Hysol US4011. compound. These two properties are very low by comparison with those of the other polyurethanes. These properties were either affected by the small addition of black colorant used to dye the material or the cure schedule employed. Without more test data, it is impossible to account for the very significant differences. The dielectric strength of the EN-7 resin $(55 \mathrm{MV} / \mathrm{m})$ is outstanding by comparison with that of about $20 \mathrm{MV} / \mathrm{m}$ for the other elastomers. The data for all properties, however, should be used with caution unless the specific effects of various environments are known for the individual compound. In that respect, the BECD test results (see preceding section) are very revealing and valuable. The performance of the Hysol USOOO9 at elevated temperatures and after prolonged exposures to high humidity was confirmed by application.

Peel Strength of Hysol US0009 Casting to Neoprene Rubber

The effectiveness of any sealant in the battery cable is predicated on its adhesion to the neoprene insert of the connector. If a good interface bond is 
TABLE 4

COMPARATIVE PROPERTIES OF POLYURETHANE EIASTOMERS

Pre Polymer

Parts Curing Agent/

100 Parts Resin

Ilardness (Shore A)

$100 \%$ Modulus, MPa

$300 \%$ Modulus, $\mathrm{MPa}$

Tensile Strength, $\mathrm{MPa}$

Elongation at break, \%

Tear strength, N/m

Brittleness Temp., Solenoid, ${ }^{\circ} \mathrm{C}$

Dielectric Strength, MV/m

Volume Resistivity,

$\Omega \cdot \mathrm{cm}$

Dielectric Constant at $23^{\circ} \mathrm{C}\left(10^{3} \mathrm{Cps}\right)$

Power Factor

Specific Gravity

Cure Schedule $\mathrm{hr} /{ }^{\circ} \mathrm{C}$

* Sandia Tab Results

**Properties Determined by BECD

***Commercial Equivalent of US0009

Adiprene
L-100* EN-7* US0009** US40II***

$11 * 18.8$

35

35

88

90

92

75

7.6

14.5

31.0
450
$8.7 \times 10^{4}$

12.4

440

36.5

4.1

$4.9 \times 10^{4}$

$6.7 \times 10^{4}$

100

$<-90$

28.3

55.1

17.2

19.7

$9.8 \times 10^{12}$

$10^{15}$

$10^{13}$

$10^{12}$

$5.8(100)$

$10.0(100)$

1.10

1.07

1.07

1.24

$48 / 25$

$4 / 71$

$1 / 100$

$16 / 80$

$-$

$1.5 / 100$

$48 / 25$

$4 / 60$

$45 / 100$

$15 / 71$

$20 / 25$

$45 / 25$

$40 / 25$ 
not achieved between the two materials, the seal will not likely impede the migration of electrolyte across the interface. BECD conducted tests with Hysol USO009 castings against two different neoprene formulations. The results are reported in Table 5. Specimens of Hysol USO009 against solvent cleaned 9-3764 neoprene exhibited a peel strength of $5.55 \mathrm{~kg} / \mathrm{cm}$ of width whereas specimens of Hysol and abraded neoprene exhibited a bond strength of $6.14 \mathrm{~kg} / \mathrm{cm}$. Specimens made with solvent cleaned 9-2964 neoprene revealed a peel strength of $5.07 \mathrm{~kg} / \mathrm{cm}$ with the Hysol. The only: drawback of these tests is that duplicate samples were not immersed in potassium hydroxide electrolyte in order to determine its effects on the Hysol/neoprene bond stability.

Comparative peel tests conducted by Caruthers ${ }^{5}$ exhibited peel strengths of $2.83 \mathrm{~kg} / \mathrm{cm}$ for the EN-7/neoprene specimen and $5.24 \mathrm{~kg} / \mathrm{cm}$ for the Adiprene/neoprene sample. The Caruthers samples were also unprimed and were solvent wiped with a 1:1 solution of alcohol/toluene as were the BECD specimens; therefore, the two sets of results were comparable. It is of interest to notice that the EN-7/neoprene bond strength is only about $50 \%$ that of the other two elastomers.

\section{Tests of Development Cables}

The testing sequence performed on the battery cables (see Table 6) at BECD and SIA are described below. Part of the units were "D" tested at BECD to determine the effectiveness of processing and of the Hysol US0009 as a cable sealant. The tests are considered progressively degradative, and all cables were not expected to survive the entire test sequence.

\section{Electrical Tests.}

After fabrication and after the " $D$ " testing, the cables were tested with the PT1100 in accordance with the procedures of PS197541 and AF360700-002. The test 


\section{$180^{\circ}$ PEEL TEST RESULTS \\ HYSOL USO0O9 CAST TO NEOPRENE RUBBER}



Preparation

*Solvent Clean

" $"$

11

60X Abrasion and

* Solvent Clean

*Solverl 61 ean

II

"1

$"$

"
Peel Strength.

Sample

1

2

3

1

6.26

6.08

6.08

1

5.37

5.19

3

5.37

5.73

5.55

3

4.65

*Solvent $=1: 1$ Mixture of Toluene and Isopropanol. 
TABLE 6

\section{Identity of Development Battery Cables}

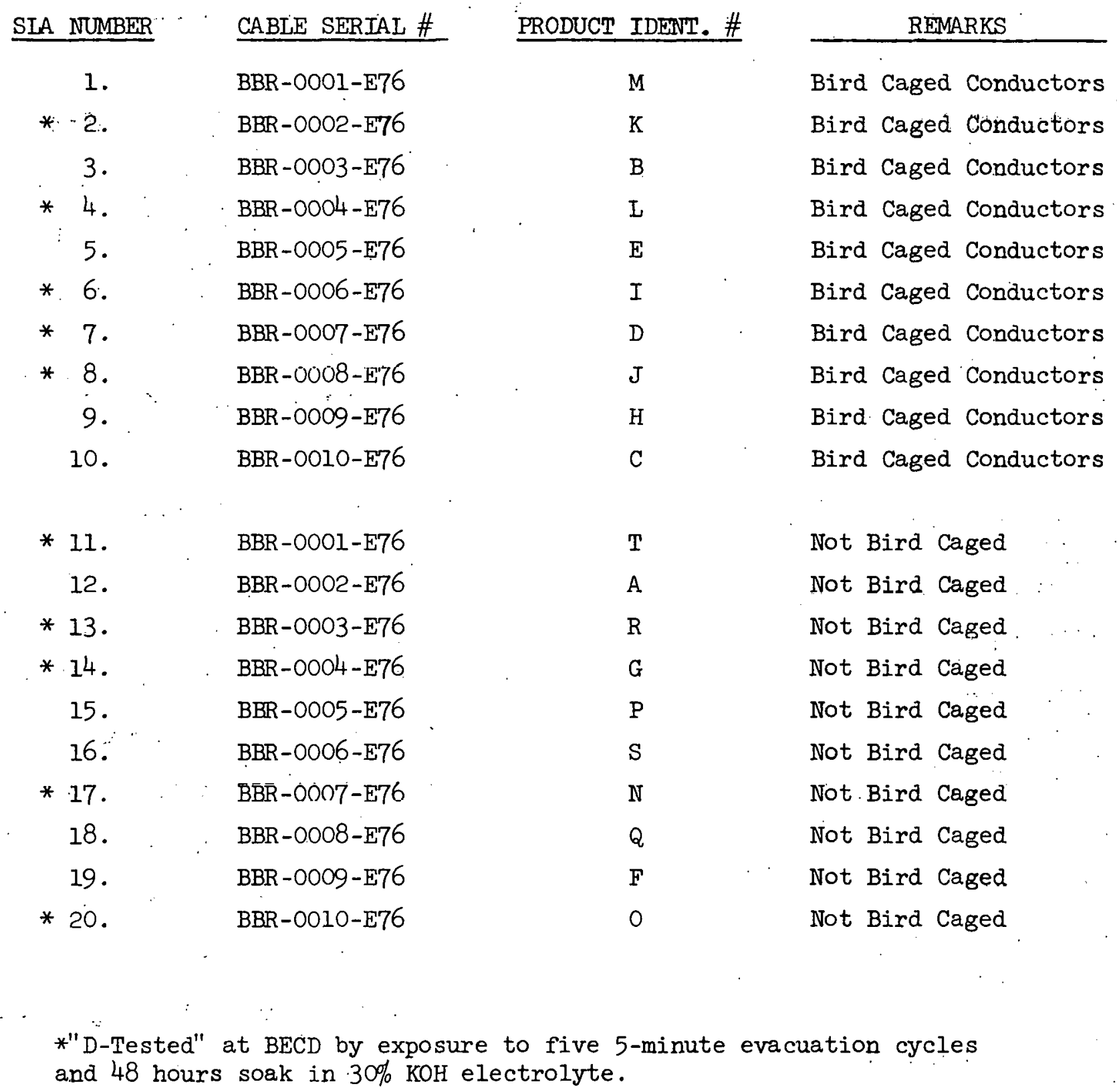


is a go-no-go test. All cables were acceptable per the DC resistance, insulation resistance, and high potential requirements.

During subsequent tests at SLA, the corresponding tests were conducted on open set-up, and variables data were obtained on DC resistance and insulation resistance (see Tables $7,8,9$, and 10).

la) DC resistance on the three cable circuits was conducted in accordance with 9990009 . The test was made using a mated pair of connectors on the three conductors. The ground circuit consisted of connecting circuit $\mathrm{C}$ to the shell of the connector. The resistance was not to exceed 30,20 and 50 milliohms on circuits $A, B$, and $C$, respectively.

1b) The insulation resistance was performed in accordance with 9990008 and was required to exceed 100 megohms.

1c) High potential was conducted per 9990006 , type 2 , and the maximum allowable leakage was not to exceed 5 milliamperes.

\section{Electrolyte Immersion Tests}

The cables, except for the connectors, were immersed in $30 \%$ potassium hydroxide (KOH) electrolyte at room temperature and at a pressure of $380 \mathrm{~mm}$ of mercury. The cables were retained under this condition for 5 minutes. This test was repeated five times in immediate sequence. Between each of these 5 tests, the room ambient pressure was restored. The cables were not removed from the electrolyte during this series of evacuations. Immediately upon removal from the electrolyte, the cables were thoroughly washed with clean water to remove the $\mathrm{KOH}$. The cables were then dried in an air circulating oven at $71^{\circ} \mathrm{C}$ for 2 hours.

The cables when dried met the electrical requirements of para. 1. (See Tables 7 and 8$)$. 
TABLE 7

ELECTRICAL TESTING OF BIRD-CAGED CABLES UNITS 1-10

ENV IRONMENTS

RESISTANCE, MILLIOHMS
CIRCUITS
A $\quad$ B C C GR

Initial At BECD

(Passed PT1100 Test)

Vacuum Immersicn

(Units, 2, 4, 6, 7, \& 8 Passed PT1100 Test)

$48 \mathrm{Hr}$. Immersion

Initial At SIA

Vacuum Immersion

$48 \mathrm{Hr}$. Immersion

Temp. Shock

Vacuum Immersion

$48 \mathrm{Hr}$. Immersion

MIL-STD 202

Vacuum Immersion

48 Ir. Immersion
INSUIATION RESISTANCE, GIGAOHMS CIRCUITS

A : $\mathrm{B} \quad \mathrm{C}$

(Passed PTl100 Test)

(Units 2, 4, 6, 7, \& 8 Passed PTl100 Test)

(Units 2, 4, 6, 7, \& 8 Passed PTII00 Test)

$\begin{array}{lll}25.1 & 18.6 & 14.1 \\ 23.8 & 17.9 & 13.5 \\ 22.8 & 17.1 & 12.8 \\ 23.2 & 17.7 & 14.1 \\ 24.4 & 18.9 & 14.0 \\ 24.4 & 18.5 & 13.7 \\ 20.2 & 15.6 & 11.8 \\ 16.6 & 13.3 & 9.4 \\ 14.8 & 12.9 & 8.0\end{array}$

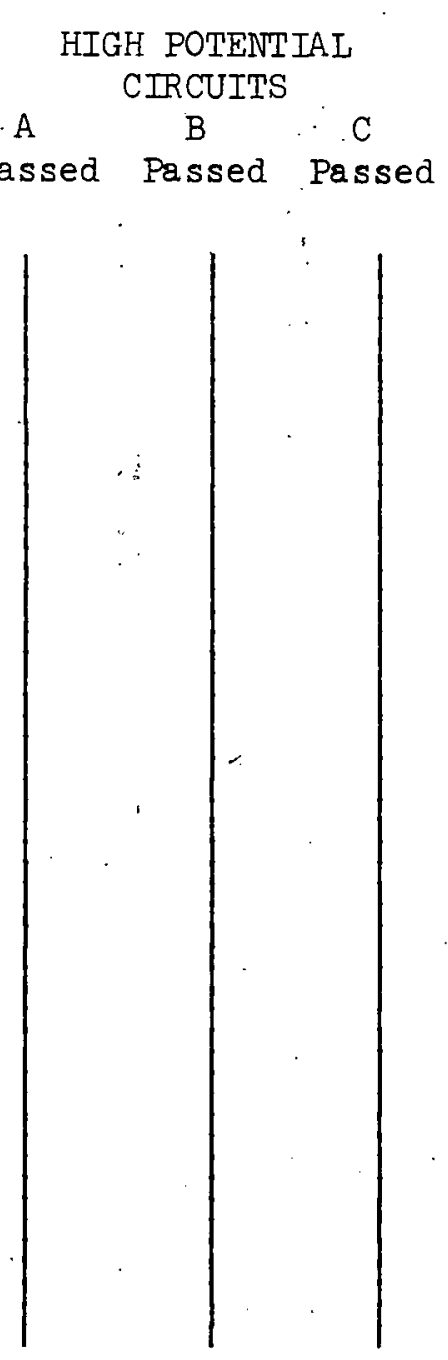


ELECTRICAL TESTING OF UNITS 11-20 NOT BIR.D-CAGED

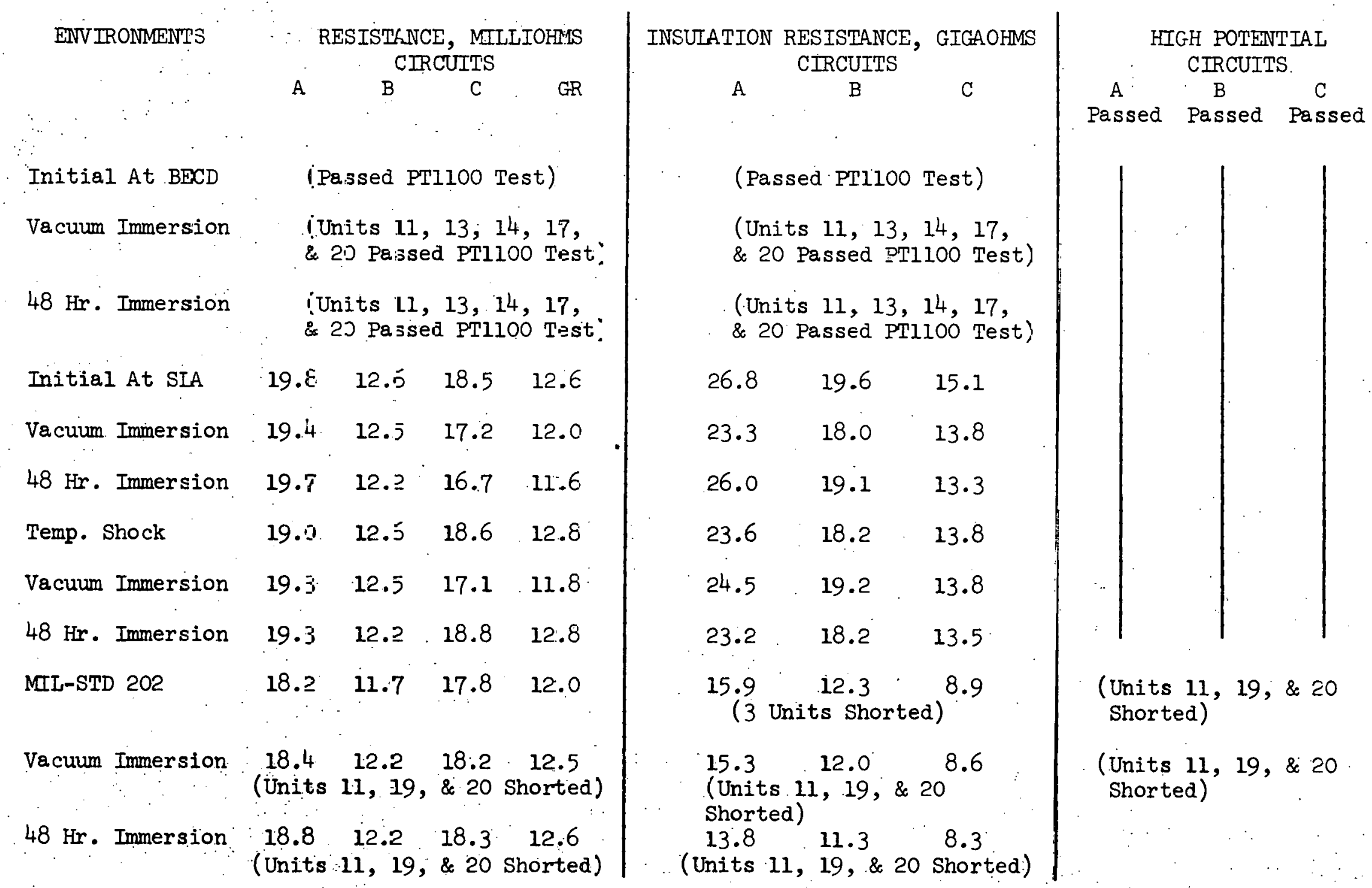


The same cables were then immersed in $30 \% \mathrm{KOH}$ electrolyte at room temperature for 48 hours. Immediately upon removal from the electrolyte, the cables were cleaned and dried.

Upon electrical retesting, the cables met the electrical requirements in para. 1. (See Tables 7 and 8 ).

As a result of the immersion tests, there shall be no visual evidence of electrolyte penetration into the encapsulation.

3. Effects of Temperature Shock

The cables after exposed to 6 temperature shock cycles from $-15^{\circ} \mathrm{C}$ to $+75^{\circ} \mathrm{C}$ stili met the electrical requirements of para. 1. (Tables 7 and 8 ).

The cables were again subjected to electrolyte immersion tests of para. 2. Both the five 5-minute cycles and the 48 hour soak were imposed. The cables then again met the requirements of paragraph one after the washing and drying cycles. (See Tables 7 and 8 ).

4. Effects of MLL STANDARD 202 Exposure

After 10 days exposure to the MIL-STD $202 \mathrm{E}$, Method $106 \mathrm{D}$, environment, the cables were wiped off and then electrically tested. The bird-caged cables still met the electricai requirements of paragraph 1 . The units were re-exposed to the elecirolyte immèrsion tests, successively cleaned and retested. The results are reported in Table 7. Except for a slight drop in insulation resistance, the cables had no't suffered any adverse effects from the consecutive environmental tests which had been imposed.

From the data in Table 8 , it is noted that three units not bird-caged failed the insulation resistance and the high potential tests after the MLL-STD exposure. After the $\mathrm{KOH}$ immersion, the same three units also failed the DC resistance test. It is of interest to observe that two of these cables (Units \#II and \#20) were part 
of the group initiaily " $D$ " tested by BECD. It is concluded that these units failed because of electrolyte seepage to the polyurethane/neoprene interface.

The sequence of tests conducted above is very severe and probably represent five or more years of service of cables attached to the MC1605B battery. The results confirm that the bird-caged units can successfully withstand the severest simulated environments whereas the units not bird-caged may perform with less reliability under the same conditions.

The test results in Tables 9 and 10 show the initial and final DC resistance and insulation resistance values, respectively, for each of the twenty test cables in this evaluation. The DC resistance remained unchanged but the insulation resistance showed a slight progressive drop from one exposure to the next.

\section{Future Work}

From this study, it is evident that additional testing should be conducted on the Hysol US0009 elastomer because of discrepancies in methods, tests, and results reported by the resin manufacturer and $\mathrm{BECD}$.

In such an evaluation; it is necessary to (1) develop an optimum cure schedule, (2) to determine the mechanical, electrical, and thermal properties of the Hysol compound in dynamic modes, and (3) to develop adhesion values which correspond to weapon requirements. 4 From this third test, it would be possible for instance to ascertain the quality of the Hysol US0009/neoprene bond after prolonged immersion in potassium hydroxide.

\section{Conclusion}

The Hysol US0009 polyurethane elastomer was successfully used as an encapsulant for battery cables. 
TABLE 9

INITIAL AND FINAL DC RESISTANCE: TESTS OF BATTERY CABLES

(READINGS IN MILLIOHMS)

\begin{tabular}{|c|c|c|c|c|c|c|c|c|}
\hline \multirow[t]{2}{*}{ CABLE } & \multicolumn{2}{|c|}{ CIRCUIT A } & \multicolumn{2}{|c|}{ CIRCUIT $B$} & \multicolumn{2}{|c|}{ CIRCUIT C } & \multicolumn{2}{|c|}{ GROUND CIRCUIT } \\
\hline & INITIAI & FINAI & INITIAI & FINAL & INITIAI & FINAL & INITIAI & FINAI \\
\hline 1. & 18.6 & 19.1 & 12.3 & 12.8 & 18.2 & 18.7 & 12.9 & 13.1 \\
\hline 2. & 18.6 & 18.7 & 12.6 & 13.0 & 18.4 & 18.6 & 13.1 & 12.9 \\
\hline 3. & 19.1 & 18.5 & 11.7 & 12.1 & 18.6 & 19.1 & 13.1 & 13.4 \\
\hline 4. & 18.7 & 19.5 & 12.4 & 11.9 & 18.3 & 18.9 & 12.8 & 13.4 \\
\hline 5. & 18.7 & 19.2 & 12.4 & 12.3 & 18.3 & 18.3 & 12.9 & 13.0 \\
\hline 6. & 18.7 & 19.1 & 12.7 & $12: 4$ & 18.7 & 19.0 & 13.4 & 13.5 \\
\hline 7. & 18.8 & 18.5 & 12.5 & 12.3 & 18.0 & 18.5 & 12.8 & 12.8 \\
\hline 8. & $19 . \varepsilon$ & 18.6 & 13.2 & 12.4 & 20.1 & 20.2 & 13.1 & 13.4 \\
\hline 9. & 18.8 & 20.3 & 12.5 & 12.4 & 18.4 & 18.8 & 13.1 & 13.0 \\
\hline 10. & 18.6 & 18.7 & 12.4 & 12.1 & 18.0 & 18.2 & 12.4 & $12 \cdot 3$ \\
\hline 11. & 18.9 & No test & 12.8 & No test & 19.0 & No test & 12.9 & No test \\
\hline 12. & 20.6 & 18.3 & 13.3 & 11.6 & 17.2 & 17.2 & 12.2 & 12.1 \\
\hline 13. & $19 \cdot 3$ & 18.6 & 12.8 & 11.7 & 17.9 & 17.1 & 12.1 & 12.4 \\
\hline 14. & 18.6 & 18.7 & 12.3 & 11.8 & 19.2 & 18.8 & 12.7 & 12.7 \\
\hline 15. & 19.1 & 18.8 & 12.6 & 12.1 & 18.7 & 18.4 & 12.6 & 12.5 \\
\hline 16. & 19.1 & 18.9 & 13.0 & 12.2 & 18.8 & 19.7 & 13.2 & 13.5 \\
\hline 17. & 19.8 & 19.5 & 12.7 & 12.2 & 18.8 & 18.5 & 12.4 & 12.7 \\
\hline 18. & 24.1 & 18.8 & 12.5 & 14.0 & 18.5 & 18.5 & 12.5 & 12.5 \\
\hline 19. & 19.1 & No test & 12.0 & No test & 18.0 & No test & 12.6 & No test \\
\hline 20. & 19.5 & No test & 11.6 & No test & 18.5 & No test & 12.6 & No test \\
\hline
\end{tabular}
and $C$. Ground circuit was made to shell of cable connector only. 
TABLE 10

$\frac{\text { INITIAI AND FINAL INSUIATION RESISTANCE TESTS CF BATTERY CABLES }}{\text { (READIINGS IN GIGAOHMS) }}$

\begin{tabular}{|c|c|c|c|c|c|c|}
\hline \multirow[t]{2}{*}{ CABLE \# } & \multicolumn{2}{|c|}{ CIRCUIT A } & \multicolumn{2}{|c|}{ CIRCUIT B } & \multicolumn{2}{|c|}{ CIRCUIT C } \\
\hline & INITIAL & FTNAI & INITIAL & FINAL & INITIAL & FINAL \\
\hline 1. & 21 & 17 & 18 & 14 & 15 & 9 \\
\hline 2. & 25 & 17 & 17 & 15 & 13 & 10 \\
\hline 3. & 29 & 17 & 22 & 14 & 16 & 9 \\
\hline 4. & 30 & 17 & 18 & 13 & 14 & 9 \\
\hline 5. & 18 & 13 & 15 & 11 & 11 & 7 \\
\hline 6. & 27 & 7 & 22 & 13 & 16 & 3 \\
\hline 7. & 25 & 15 & 19 & 13 & 15 & 8 \\
\hline 8. & 24 & 15 & 18 & 12 & 14 & 8 \\
\hline 9. & 29 & 15 & 19 & 12 & 13 & 8 \\
\hline 10. & 23 & 15 & 18 & 12 & 14 & 9 \\
\hline 11. & 22 & Short & 16 & Short & 12 & Short \\
\hline 12. & 25 & 15 & 18 & 11 & 14 & 9 \\
\hline 13. & 21 & 10 & 18 & 11 & 13 & 8 \\
\hline 14. & 25 & 14 & 18 & 10 & 14 & 8. \\
\hline 15. & 20 & 11 & 17 & 9 & 12 & 7 \\
\hline 16. & 31. & 0.001 & 23 & 9 & 17 & 0.003 \\
\hline 17. & 27 & 16 & 20 & 11 & 15 & 8 \\
\hline 18. & 33 & 17 & 16 & 15 & 18 & 10 \\
\hline 19. & 29 & Short & 23 & Short & 16 & Short \\
\hline 20. & 35 & 0.09 & 27 . & 14 & 20 & 0.09 \\
\hline
\end{tabular}

Test was made by connecting one lead $\vec{D}$ the assigned circuit and tying all others together. 
It was necessary to pre-seal the conductors within the cable. with thickened Hysol in order to provide a consistently reliable barrier against the migration of electrolyte.

The Hysol compound exhibited excellent mechanical and electrical stability after exposures to elevated temperatures and high humidity.

The adhesion of Hysol USO009 to neoprene exceeded that of EN-7 polyurethane by $100 \%$.

Development cables sealed with Hysol survived $\mathrm{KOH}$ electrolyte immersions which probably represented five or more years of in-field service. These test units also retained almost unchanged their initial DC resistance, insulation resistance; and high potential characteristics after consecutive exposures to electrolyte, tempera.ture shock, and MIL-STD 202 environments.

Hysol USO009 should be evaluated at greater length for its mechanical, electrical, thermal, and hydrolytic properties. 


\section{References}

1. Uncl. Ltr, Daniel Fritz, Jr., Bendix ECD to Goerge Voida, 2356, dtd $2 / 3 / 76$.

2. George Voida, Design, Development, and Testing of a Cable Assembly for Use in Severe Electrochemical Environments, SC-DR-69-398, November 1969.

3. George Voida, Evaluations of EN-7 Encapsulant Used in Battery Cables; GAND76-0073, February 1976.

4. Uncl.. Ltr., D. J. Caruthers D/814 Bendix, KC to George Voida, 2356, dtd $8 / 17 / 76$, subject, Use of Hysol's USO009 Compound as a Material for Cable/Connector Construction.

5. Uncl. I.tr., D. J. Caruthers D/814, Bendix, KC to T. J. Husby D/862 Bendix, KC, dtd $5 / 2 / 74$, subject, Adhesion of Conathone EN-7 to Materials Commonly Found in Electronic Assemblies. 
Distribution:

Union Carbide

Oak Ridge, Tenn. 37830

Attn: Jack Thompson, D/25

Lawrence Iivermore Laboratories

P. O. Box 808

Livermore, Calif. 94550

The Bendix Corp.

P. 0. Box 1159

Kansas City, MO 64141

Attn: J. C. McCoy, D/862

Mason \& Hanger-Silas Mason Co., Inc.

P. O. Box 647

Amarillo, Texas 79177

Attn: Library

2150

2154

2154

5813

9512

C. M. Tapp

G. H. Donaldson

G. Voida (2)

R. G. Kepler

Attn: N. J. DeLollis

A. J. Quant

Attn: W. W. Kuhn

3141 C. A: Pepmueller (Actg.) (5)

3151 W. L. Garner (3)

For TITAA/T.T.

3171-i R. P. Campbell (25)

8266 E. A. Aas (2) 